\title{
REVISANDO EL SEMINARIO PERMANENTE DEL DEPARTAMENTO DE DERECHO. DICIEMBRE 2OII-DICIEMBRE 2012
}

\author{
Raúl SUSÍN BETRÁN \\ Director del Departamento De Derecho \\ PROFESOR TITUlar DE FilOSOFÍA DEL DERECHO \\ UNIVERSIDAD DE LA RIOJA
}

A finales de 20II el Departamento de Derecho decidió aceptar la propuesta de su equipo directivo de revisar una actividad, su Seminario Permanente, una vez que se había llegado a la décima edición y el paso del tiempo invitaba a ello.

Es cierto que todo cambio supone un riesgo y más en una actividad que había tenido una aceptación más que suficiente y podía continuar más tiempo con su estructura y dinámica inicial; pero también es cierto que un cambio, consciente, reflexivo y voluntario, siempre es reflejo de que ese colectivo o esa institución que lo promueve están vivos y son capaces de reaccionar de forma sensible a las necesidades de cada momento.

La confluencia de distintos factores, económicos y académicos, invitó a pensar el cambio y a aprovechar el mismo para dotar de más dinamismo al Seminario, a la vez que se recuperaba la idea de que el Seminario Permanente debería ser una de las señas de identidad del Departamento de Derecho; un espacio en el que mostrar los trabajos, intereses e inquietudes de los miembros del Departamento, pero también un espacio en el que confluir con el resto de la comunidad universitaria, e incluso más allá de esta, con la sociedad en general, y en el que poner de manifiesto que el Departamento de Derecho es docencia, pero también algo más que docencia.

Así, desde que se puso en marcha esta nueva versión del Seminario Permanente se han realizado distintos congresos, jornadas y seminarios a los que han asistido investigadores de distinta procedencia y formación, y público de los estudios jurídicos, pero también de otras disciplinas sociales y humanas y de fuera de la Universidad de La Rioja.

En las distintas actividades, instituciones o proyectos de investigación han ido aportando colaboración o financiación que ha quedado oportunamente reflejada en cada momento, pero, sin duda, a quien hay que agradecer el desarrollo de las actividades es al capital humano del Departamento que con sus iniciativas ha llenado de contenido esta estructura.

Aunque cada una de las actividades ha quedado recogida en un histórico que por cursos académicos se puede encontrar en la página web del Departamento de Derecho 
(www.unirioja.es/dptos/dd/actividades.shtml) y en el que el lector podrá encontrar cumplida información sobre estas actividades, me parece conveniente hoy citar las actividades que se han realizado amparadas por este Seminario Permanente e impulsadas, como digo, por profesores de distintas áreas de conocimiento: administrativo, civil, historia del derecho, mercantil, procesal y filosofía del derecho.

Así, desde finales de 2011 y hasta diciembre de 20I2, un año natural, las actividades han sido: Congreso Nacional: Protección jurídica, responsabilidad penal y mediación en justicia de menores (diciembre de 20II); Jornada de técnica y argumentación legislativa (febrero de 20I2); Congreso Internacional: La revisión de las normas europeas y nacionales de protección de los Consumidores (marzo 20I2); Jornada sobre arbitraje recientes reformas y perspectivas de futuro en el arbitraje nacional e internacional (abril 20I2); Seminario: Problemas actuales del derecho y la gestión del agua en España: unidad de cuenca y planificación (junio 20I2); Congreso Nacional de Derecho agrario. Agricultura, ambiente y alimentación (septiembre 20I2); 200 años de constitucionalismo español (noviembre-diciembre de 20I2); Jornada sobre Derecho y discapacidad (diciembre 20I2).

Finalmente, en la idea de que el Departamento Derecho debe contribuir a que la Universidad establezca vínculos con la sociedad y a que, sin olvidar el rigor académico que le caracteriza, intente poner antídotos a la opacidad que, en ocasiones, reviste a esta institución, se han realizado, en el marco del Seminario Permanente y a lo largo de 20I2, otras dos actividades que llenaron el aula magna de la Universidad y a la que asistieron numerosas personas de fuera de la comunidad universitaria. Así, el i6 de abril, Teresa Fernández de la Vega, vicepresidenta del Gobierno de España entre 2004 y 2010 y Consejera Permanente del Consejo de Estado, impartió una conferencia sobre cuestiones ligadas a la crisis económica, la ciudadanía y el Estado del bienestar; y el i 6 de octubre, en colaboración con el Grupo de investigación de Igualdad y Género de nuestra Universidad, tuvo lugar la conferencia «Las leyes de violencia en México», impartida por Marcela Lagarde, diputada del Congreso Federal Mexicano entre 2003 y 2006, promotora de la Ley general mexicana de acceso de las mujeres a una vida libre de violencia y una de las autoras de referencia dentro del feminismo latinoamericano. 